Annals of Plant Sciences

ISSN: 2287-688X

OPEN ACCESS

Research Article

\title{
Detection of Aspergillus flavus using PCR method from fungus infested food grains collected from local market
}

Renu Khare ${ }^{1,2}$, M.K.Agarwal ${ }^{2}$, Sameer S. Bhagayavant ${ }^{1}$, Poonam Verma ${ }^{3}$, D.P.Nagar ${ }^{2 *}$

${ }^{1}$ School of Studies Biotechnology, Jiwaji University, Gwalior, Madhya Pradesh, India

2Biotechnology Division, Defence Research and Development Establishment, Gwalior, Madhya Pradesh, India

${ }^{3}$ State Forensic Science Laboratory, Sagar Madhya Pradesh, India.

Received: 1/4/2018; Accepted: 1/27/2018

\begin{abstract}
India is an agrarian country two-thirds of its population is engaged directly or indirectly in agricultural activities. In recent years many food borne pathogens have become major threat to public health and safety. The consumption of contaminated food grains or products has been considered to be the leading source of human food borne infections. Surveillance studies have provided data and a better understanding into the existence and spread of food borne pathogens. Aflatoxins produced by Aspergillus species are important toxic secondary metabolites known for their impacts on animal and human health, and their effects on the economic loss of key grain and nut crops. Several molecular techniques (including multilocus sequence typing, pulsed field gel electrophoresis, DNA sequencing, multiplex PCR, RAPD, and many more) are available for detection and characterisation of pathogenic microorganisms from food samples, which provide reliable epidemiological data for tracing the source of infections. Present study highlights the possible use of PCR technique, in surveillance and detection of $A$. flavus in fungal infested food grains. The current study was carried out to elucidate the infestation of aflatoxin producing fungus on both kharif (groundnut, rice and maize) and Rabi crops (wheat, gram and soybean). Total 15 samples were collected randomly from local market of Gwalior (M.P). Out of fifteen only nine $(60 \%)$ samples were found to be Aspergillus positive. Seven samples were infested by Aspergillus flavus and two by $A$. niger. The selected fungal isolates were identified by amplifying aflR gene of $A$. flavus in Thermo Cycler.
\end{abstract}

Keywords: Aspergillus flavus, Aflatoxins, aflR, Mycotoxins, Polymerase chain reaction, Primers

\section{Introduction}

Aflatoxins are mycotoxins produced by the genus Aspergillus that grow on food grains and many other agricultural crops. The molds that are major producer of aflatoxins are Aspergillus flavus [1] and Aspergillus parasiticus [2]. Aflatoxin B1 is considered as a class 1 human carcinogenic activity [3]. The incidence of aflatoxin in food and feed is relatively high in subtropical and tropical regions where the warm and humid climate provides optimal conditions for the growth of moulds [4]. India is an ideal country for problems of aflatoxin to develop since it has high temperature and high moisture level during the rainy season. There are more than 20 aflatoxins [5] having six major compounds such as aflatoxin B1 (AFB2), aflatoxin B2 (AFB2), aflatoxin G1 (AFG1), aflatoxin G2 (AFG2; [6], aflatoxin M1 (AFM1) and aflatoxin M2 (AFM2). The four AFB1, AFB2, AFG1, and AFG2 are naturally occurring aflatoxins, while aflatoxin M1 (AFM1) and M2 (AFM2) are the hydroxylated metabolites of AFB1 and AFB2 [7, 8]. They are odorless, tasteless and colorless. All aflatoxins are closely similar in structure and form a unique group of highly oxygenated, naturally found heterocyclic compounds.

\section{${ }^{*}$ Corresponding Author:}

Dr. D.P. Nagar,

Biotechnology Division,

Defence Research and Development Establishment,

Jhansi Road Gwalior-474002, Madhya Pradesh, India.

E-mail: vijaynagar2001@yahoo.co.in
The aflatoxin B1 biosynthesis involves the twenty three enzymatic reactions starting with acetyl-CoA. A total of fifteen intermediate precursors are recognized in the biosynthesis pathway [9] involving twenty five genes, clustered in a 75-kb DNA region [10]. The sequences of the genes involved in aflatoxin biosynthesis come into view to be highly conserved among $A$. flavus and $A$. parasiticus [11]. There is no specific PCR for any one of the four biologically produced aflatoxins [12]. The late stages of AFB1 synthesis are carried out by two enzymes, a methyltransferase encoded by the aflP (omt $A$ ) gene that converts sterigmatosystin to Omethylsterigmatocystin and an oxidoreductase encoded by the aflQ (ord A) gene that converts Omethylsterigmatocystin to aflatoxin B1. Bhatnagar $e t$ al., in 1991 [13] presented evidence that these later stages of AFB1 and AFB2 synthesis are catalyzed by common enzymes that use separate precursors as substrates for each toxin. Most important requirement for avoiding the consumption of aflatoxin contaminated food is the rapid identification of mycotoxin producing fungi from food samples is usually by traditional dilution plating method. Such method is costly, time consuming and labor intensive and requires expertise. Keeping these problems in mind we 
utilized the already available sequence of PCR primers [14] to identify the $A$. flavus from fungus infected food grains collected from local market.

\section{Materials and Methods}

\section{Sample collection}

The samples of key grains shown high infestation and crop damage were collected randomly in sterile poly bags from local market of Gwalior (India). From the market located adjacent to the study centre $1 \mathrm{~kg}$ of each groundnut, gram, maize, rice, soybean and wheat samples were collected by following random sampling technique. From the collected samples, the fungal infected grains were separated out aseptically. Their weight was measured using a digital balance. The percentage of infected nuts and grains present in the collected samples were calculated based on the counts and weight. The same sampling procedure was followed for collecting all the food grains.

\section{Isolation and maintenance of fungus}

For fungal isolation direct plate inoculation technique was used using 50 highly fungal infested crop grains obtained from local market located in the vicinity of the research centre. The individual grains were directly inoculated onto potato dextrose agar (PDA) plates and incubated for 5 days at $35^{\circ} \mathrm{C}$ along with a negative control plate with no inoculation. The observed colonies were subcultured onto Rose-Bengal chloramphenicol media. The colony morphology and appearance of Aspergillus strains differ based on the media used. Hence pure cultures of Aspergillus species were grown on three fungal differential media - Czapek Extract Yeast Agar (CYA), Malt Extract Agar (MEA), and Czapek Dox Agar (CZA) and incubated at $25^{\circ} \mathrm{C}$ for seven days [15]. Colony morphological characteristics of isolates were observed both in the top side and bottom side of the media. For identification to species level colony morphology, conidiophores, conidial arrangement (Fig. 2) were observed in microscope after wet mount in lactophenol cotton blue stain. The fungal colonies suspected to be of $A$. flavus were picked and subcultured for DNA isolation. The fungal isolates were maintained on potato dextrose agar media. Cultures were sub-cultured periodically from 5-day-old slant cultures (Fig. 1) isolated from food crop samples. The identification of A. flavus was further confirmed by amplification of afR gene by PCR method.

\section{DNA isolation}

The Genomic DNA extraction, from pure fungal cultures was done according to available method [16] with slight modification manually by washing the mycelial pellets twice with $1 \mathrm{ml}$ of distilled water. To a $1.5 \mathrm{~mL}$ Eppendorf tube containing $500 \mu \mathrm{L}$ of lysis buffer $(400 \mathrm{mM}$ Tris- $\mathrm{HCl},[\mathrm{pH} 8.0], 60 \mathrm{mM}$ EDTA [pH 8.0], 150mM NaCl, 1\% sodium dodecyl sulfate), a small lump of mycelia from young culture is added by using a sterile toothpick, with which the chunk of mycelia is disrupted. The tube is then left at room temperature for $15 \mathrm{~min}$. After adding $150 \mu \mathrm{L}$ of potassium acetate $(\mathrm{pH} 4.8$; which is made of $60 \mathrm{~mL}$ of $5 \mathrm{M}$ potassium acetate, $11.5 \mathrm{~mL}$ of glacial acetic acid, and $28.5 \mathrm{~mL}$ of distilled water), the tube is vortexed and centrifuged at $10000 \times \mathrm{g}$ for $1 \mathrm{~min}$. The supernatant is transferred to another $1.5 \mathrm{~mL}$ Eppendorf tube and centrifuged again as described above. After transferring the supernatant to a new $1.5 \mathrm{~mL}$ Eppendorf tube, an equal volume of isopropyl alcohol is added. The tube is mixed by brief vertexing. The tube is centrifuged at $10000 \times \mathrm{g}$ for $3 \mathrm{~min}$, and the supernatant is discarded. The pellet thus obtained is washed in $300 \mu \mathrm{L}$ of $70 \%$ ethanol. After centrifugation of sample at 10000xg for $1 \mathrm{~min}$, the supernatant is discarded. The DNA pellet is air dried and dissolved in $50 \mu \mathrm{L}$ of triple deionized water, and $1 \mu \mathrm{L}$ of this purified DNA is used as a template in $25 \mu \mathrm{L}$ of PCR reaction mixture.

\section{Primers}

Primer sequence already available in literature [14] were used to amplify the aflatoxin regulatory gene (aflR) fragments of aflatoxigenic fungal genomic DNA. The sequences of the forward and reverse primers of the aflR gene used were (5'AACCGCATCCACAATCTCAT-3') and (5'AGTGCAGTTCGCTCAGAACA-3'). The primers used in present study cover the region from 540 to 1338 of Aflatoxin regulatory gene with product size of 798 base pairs [17].

\section{Polymerase chain reaction (PCR)}

The reaction conditions for the PCR assay were optimized to ensure that all of the target gene sequences were satisfactorily amplified. The polymerase chain reaction was performed in $25 \mu \mathrm{L}$ of reaction mixture using genomic DNA as template isolated by the method described earlier. The genomic DNA was amplified in Icycler (Bio$\mathrm{Rad}, \mathrm{USA}$ ) with 30 cycles, each cycle at $94^{\circ} \mathrm{C}$ for 3 $\min$ for denaturation, $0.45 \mathrm{~min}$ at $55^{\circ} \mathrm{C}$ for annealing, $1.25 \mathrm{~min}$ at $72^{\circ} \mathrm{C}$ for extension and a 10 min final extension at $72^{\circ} \mathrm{C}$. To check the specificity of primers the PCR was also performed as above using ATCC 367 as a standard of $A$. flavus and the genomic DNA of five different microorganisms (Staphylococcus aureus, S. epidermidis, E. coli, Clostridium botulinum, and Penicillium notatum).

The amplified PCR products were resolved by gel electrophoresis in a $1.5 \%$ agarose (Sigma) gel stained in $0.5 \mathrm{mg} / \mathrm{ml}$ ethidium bromide in TBE buffer at $100 \mathrm{~V}$ for $40 \mathrm{~min}$. The DNA bands resolved on agarose gel were visualized in UV transilluminator and photographed. The sizes of the amplicon was estimated after comparing with a commercial 100 bp DNA ladder on agarose gel. 


\section{Results}

Fungal Infection percentage

Out of the collected $1 \mathrm{~kg}$ of each crop grains when the infected nuts/grains were separated and weighed they showed an average of $100 \mathrm{gm}$ of weight giving an infection weight percentage of 10 and an infection count percentage of 13.

\section{Fungal isolation in basal media}

The colour and morphology of colony was used as the first level of identification. From the observations made in infested food grains the fungal growth was seen in all the inoculated plates except negative control. Colonies granular, velvety, or wooly and yellow or yellow-brown; the reverse is golden to red-brown were suspected to be of $A$. flavus while colonies in shades of black and brown colour as Aspergillus niger. All the isolates belonging to genus Aspergillus were selected for the study. Other characteristic features considered were soluble pigments formation and production of exudates in the media. Based on morphological similarity of fungal colonies from infested crop samples, the number of $A$. flavus and $A$. niger, isolates obtained were 56 and 16 respectively.

\section{Analysis of fungal genes by PCR}

In our study the PCR reaction was targeted against aflatoxin synthesis regulatory gene (aflR). Genomic DNA isolated from aflatoxigenic Aspergillus flavus (ATCC 367) and five other microbes were first used as template and PCR was performed using forward and reverse primer of aflR gene. In gel electrophoresis of PCR product and amplicon corresponding to $798 \mathrm{bp}$ in size was seen only in positive control sample of $A$. flavus (ATCC 367) but not in the other samples, which clearly indicated that the primers were specific for $A$. flavus only (Fig. 3). After fidelity test of primers PCR was carried out with fungal isolates, which included 7 strains of $A$. flavus; 2 strains $A$. niger (Table 1$)$. All $A$. flavus strains reacted positively with the aflR gene primer set, while no amplification was seen in case of $A$. niger (Fig. 4).

Table 1. Isolated fungal isolates from different food grains.

\begin{tabular}{|c|c|c|c|}
\hline $\begin{array}{l}\text { S.No } \\
\text {. }\end{array}$ & Crop samples & Infestation & Fungal isolates \\
\hline 1. & Groundnut & + & flavus (I1) \\
\hline 2 & Groundnut & - & - \\
\hline 3 & Groundnut & - & A. flavus (I2) \\
\hline 4. & Gram & - & - \\
\hline 5 & Gram & + & flavus (I3) \\
\hline 6 & Gram & - & A. flavus (I4) \\
\hline 7. & Maize & + & A. $\quad$ flavus (I5) \\
\hline 8 & Maize & - & - \\
\hline 9 & Maize & - & - \\
\hline 10 & Rice & + & A.flavus (I6) \\
\hline 11 & Rice & - & - \\
\hline 12 & Soya bean & + & flavus (I7) \\
\hline 13 & Soya bean & + & niger (I8) \\
\hline 14 & Wheat & - & - \\
\hline 15 & Wheat & - & A. niger (I9) \\
\hline
\end{tabular}

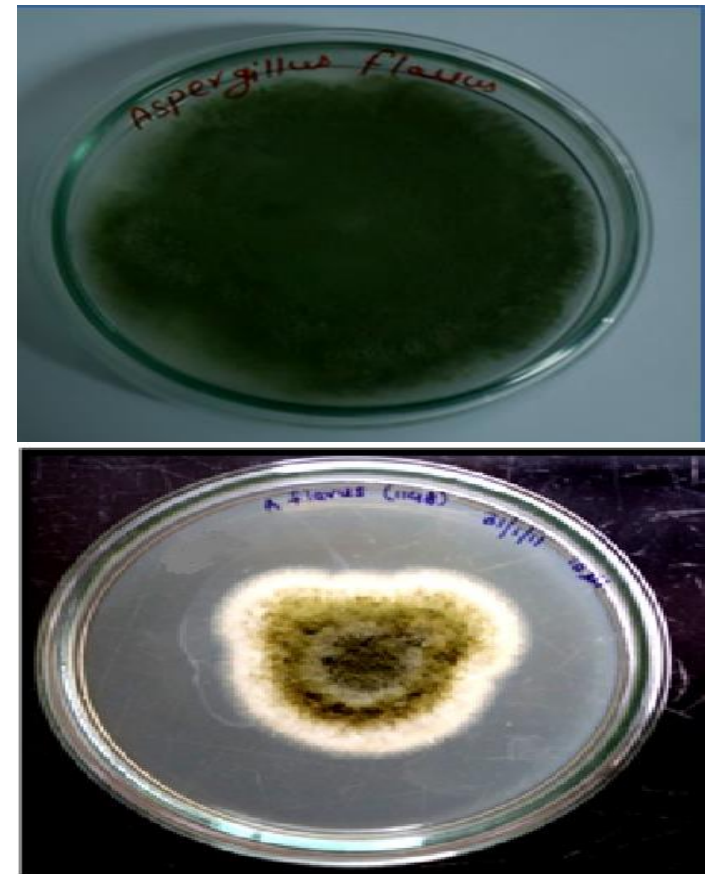

Figure 1. Pure culture of Aspergillus flavus isolated from food grains
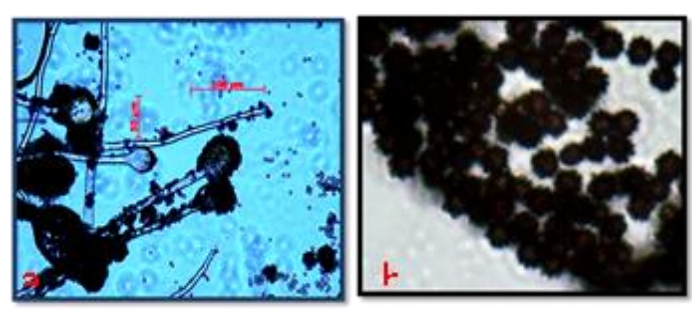

Figure 2. Micro morphological Characteristics of (a) Aspergillus flavus (b) A. niger under bright field microscope.

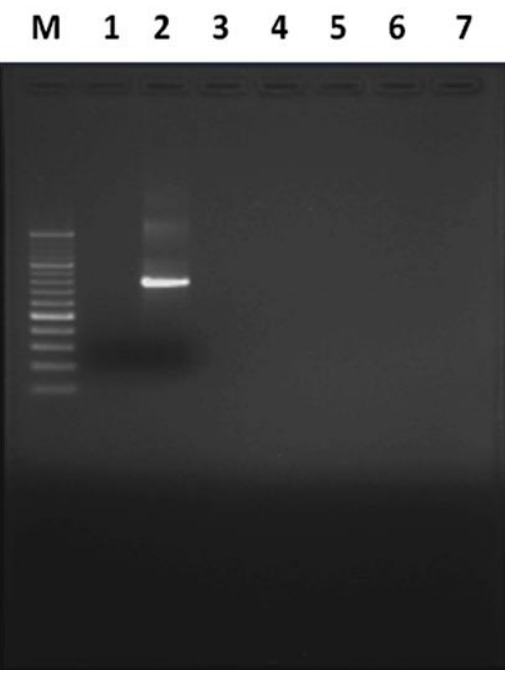

Figure 3: Fidelity analysis of primer by performing PCR using A. flavus (ATCC 367) as a standard and other genomic DNA as experimental controls. Lanes: (M) DNA ladder (100bp); (1) Negative control (without template); (2) A. flavus ATCC 367; (3) S. aureus; (4) E. coli; (5) C. botulinum; (6) P. notatum; (7) S. epidermidis 
M 122334556778091011

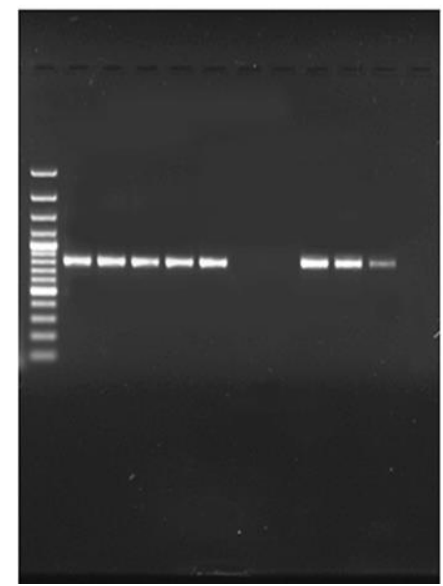

Fig. 4. Agarose gel analysis of PCR products obtained from different fungal species Lanes: (M) DNA ladder (100bp) (1) A. flavus ATCC367 (2) $A$. flavus (I1) (3) A. flavus (I2) (4) $A$. flavus (I3) (5) $A$. flavus (I4) (6) A. niger (I8) (7) A. niger (I9) (8) $A$. flavus (I5) (9) A. flavus (I9) (10) A. flavus (I10) (11) Environmental control (without template)

\section{Discussions}

Due to the toxic and carcinogenic properties of aflatoxins, there is an urgent need to develop sensitive, rapid, and specific technique for the identification of aflatoxin producing $A$. flavus from food samples. The DNA amplification technique PCR allows the specific and exponential synthesis of a targeted DNA fragments with the use of small, specifically designed DNA fragments (primers). A number of researchers have used the PCR assay to identify the specific pathogen/organism or contamination of food samples. The PCR is one of the easiest techniques for the detection of any microorganism in samples. Thus we observed that all 7 A. flavus strains reacted positively with the primer set (Fig. 4) no amplification were observed with DNA from other Aspergillus species (A. niger), which is quite similar to the observation of Shapira et al., (1996) [18] that identified and sequenced the three genes, versicolorin A dehydrogenase gene (ver1), sterigmatocystin- o-methyltransfersase 1 gene (omt-1), and an aflatoxin biosynthesis regulatory gene (apa-2 now called the aflR gene) from Aspergillus parasiticus. The aflatoxin gene cluster in $A$. flavus and $A$. parasiticus contains 25 genes reaching about $70 \mathrm{~kb}$. The pathway step, aflR, which represents a positive regulatory gene coding for a sequence-specific, is a zinc finger DNA-binding protein. Manonmani et al. [19] in 2005 used an indigenously specific primer pair for the aflatoxin regulatory (aflR) gene assessed the presence of aflatoxigenic fungi in foodstuffs. In this study DNA isolated from aflatoxigenic Aspergillus flavus ATCC 367 was first used as template and PCR carried out with primers for portion of the aflatoxin biosynthetic target gene aflR. An amplicon corresponding to $798 \mathrm{bp}$ in size was seen after agarose gel electrophoresis [20]. Here PCR was tested with 9 fungal isolates (Table 1) which included 7 strains of $A$. flavus and 2 strains of $A$. niger.

\section{Conclusions}

Several detection methods have been invented and are widely used to detect and differentiate type of pathogens from, outbreak, clinical samples and from epidemiological studies. After discovery of two or more primers method the discriminatory power of the detection or identification technique employed have drastically increased. The primers used in this study amplified only $A$. flavus genes, while the amplification of other Aspergillus species (A. niger) was not obtained, which clearly indicate that PCR method may be utilised to distinguish Aspergillus flavus from other Aspergillus species. Furthermore this technique may be applied to the screening of food grains sold in the market for presence of aflatoxin producing fungus $A$. flavus. The negative results of PCR assay may be considered as indicator of food sample free from $A$. flavus infestation. The usefulness of this PCR assay developed so far to screen quality and safety in food industries was already established.

\section{Acknowledgements}

The authors are grateful to the Head, Biotechnology Division, Ph.D. guide and Director, Defence Research and Development Establishment, Jhansi Road, Gwalior-474002, for providing facilities and encouragement.

\section{References}

1. Bankole S A, BM Ogunsanwo and OO Mabekoje. "Natural occurrence of moulds and aflatoxin B1 in melon seed from markets in Nigeria." Food Chem Toxicol 2004; 42: 1309-1314.

2. Leontopoulos D, A Siafaka and P Markaki. "Black olives as substrate for Aspergillus parasiticus growth and aflatoxin B1 production." J. Food Microbiol 2003; $20,119-126$

3. Bennet J W and M Klich. "Mycotoxins." Clin Microbiol Rev 2003; 16: 497-516.

4. Bintvihok A. "Aflatoxin contamination in shrimp feed and effect of aflatoxin addition to feed on shrimp production.” J Food Protection 2003; 66(5):882885.

5. Kumar P, D K Mahato, M Kamle, T K Mohanta and S G Kang. "Aflatoxins: A Global Concern for Food Safety, Human Health and Their Management." Front Microbiol 2016; 7: 2170.

6. Inan F, M Pala, and I Doymaz. "Use of ozone in detoxification of aflatoxin B1 in red pepper." J Stored Prod Res 2007; 43: 425-429.

7. Giray B, G Girgin, A B Engin, S Aydın and G Sahin "Aflatoxin levels in wheat samples consumed in 
some regions of Turkey." Food Control 2007; 18: $23-$ 29.

8. Hussain I and J Anwar. "A study on contamination of aflatoxin M1 in raw milk in the Punjab province of Pakistan." Food Control 2008; 19: 393-395.

9. Meyers D, G Obrian, W Du, D Bhatnagar and G Payne. "Characterization of aflJ, a gene required for conversion of pathway intermediates to aflatoxin." Appl Environ Microbiol 1998; 64: 3713-3717.

10. Bhatnagar D, J Cary, $\mathrm{K}$ Ehrlich, $\mathrm{J} \mathrm{Yu}$, and $\mathrm{T}$ Cleveland. "Understanding the genetics of regulation of aflatoxin production and Aspergillus flavus development." Mycopathology 2006; 262: 255-266.

11. Yu J, P K Chang, K C Ehrlich, J W Cary, D Bhatnagar, T E Cleveland, G A Payne, J E Linz, C P Woloshuk and J W Bennett. "Clustered pathway genes in aflatoxin in biosynthesis." Appl Environ Microbiol 2004; 70: 1253-1262.

12. Levin R E. "PCR detection of aflatoxin producing fungi and its limitations." Int J Food Microbiol 2012; 1:156(1):1-6.

13. Bhatnagar D. "Enzymological evidence for separate pathways for aflatoxin B1 and B2 biosynthesis." Biochemistry 1991; 30: 4343-4350.

14. Hashim A, A Al-Kazaz and Abdulmalek. "PCR Detection of Aspergillus flavus Isolates for Aflatoxin B1 producer." Journal of Biotechnology Research Center 2013; 7 (3): 81-89.
15. Thilagam R, N Hemalatha, E Poongothai and G Kalaivani. "Identification of Aspergillus species isolated from corn and peanuts in storage godowns." Int J Pharm Bio Sci 2016; 7(4): 600- 606.

16. Aamir S, S Sutar, S K Singh and A Baghela. "A rapid and efficient method of fungal genomic DNA extraction, suitable for PCR based molecular methods." Plant Pathology and Quarantine 2015; 5(2):74-81.

17. Farber P, R Geisen and W H Holzapfe. "Detection of aflatoxigenic fungi in figs by a PCR reaction." Int J Food Microbiol 1997; 36: 215-220.

18. Shapira R, N Paster, O Eyal, M Menashero, A Mett and R Salomon. "Detection of aflatoxigenic mold in grain by PCR." App Environ Microbiol 1996; 62: 32703273.

19. Manonmani H K, S Anand, A Chandrashekar and E $\mathrm{R}$ Rati. "Detection of aflatoxigenic fungi in selected food commodities by PCR." Process Biochem 2005; 40: 2859-2864.

20. Mateo E M, J G Serna, B Patiño and M Jiménez. "Aflatoxins and ochratoxin A in stored barley grain in Spain and impact of PCR-based strategies to assess the occurrence of aflatoxigenic and ochratoxigenic Aspergillus spp." Intl J Food Microbiol 2011; 149(2): 118-26.

\section{Cite this article as:}

Renu Khare, M.K.Agarwal, Sameer S. Bhagayavant, Poonam Verma, D.P.Nagar. Detection of Aspergillus flavus using PCR method from fungus infested food grains collected from local market. Annals of Plant Sciences 7.2 (2018) pp. 2073-2077.

do $\mathrm{http}: / / \mathrm{dx}$.doi.org/10.21746/aps.2018.7.2.16 